\title{
LETRAMENTO DIGITAL E AUDIOVISUAL COMO POTENCIALIZADORES DA APRENDIZAGEM COLABORATIVA DO PORTUGUÊS E DO ESPANHOL COMO LÍNGUAS ADICIONAIS
}

\author{
Élida Ferreira LINS* \\ Fábio Marques de SOUZA**
}

- RESUMO: Este estudo tem por objetivo discutir o letramento digital e o audiovisual como potencializadores da aprendizagem colaborativa do português e do espanhol como línguas adicionais. As tecnologias digitais de informação e comunicação são caminhos bastante promissores para o campo educacional e, em especial, para o ensino de línguas em uma perspectiva linguístico-cultural. Nesse viés, podemos observar o teletandem como instrumento potencializador de práticas reais e autênticas no que diz respeito ao contato com línguas, em um universo intercultural. Assim sendo, reconhecemos a importância do letramento digital e do campo audiovisual para fomentar o processo de ensino-aprendizagem por, dentre outros motivos, aprimorar a autenticidade linguístico-cultural sugerida pelo teletandem. Desta forma, observamos, nessa discussão, que os estudantes, quando dominam competências inerentes ao letramento digital, utilizam com sucesso os recursos audiovisuais e garantem bons resultados na aquisição de línguas, o que pode ser comprovado através de práticas realizadas no contexto do Teletandem institucional.

- PALAVRAS-CHAVE: Letramento digital. Recursos audiovisuais. Ensino-aprendizagem de línguas. TDICs. Teletandem.

\section{Introdução}

As tecnologias digitais de informação e comunicação, doravante TIDCs, apresentam presença marcante no contexto social e educacional vigente. Isso corresponde afirmar uma sociedade sediada pela diversidade de serviços/benefícios advindos desse novo

\footnotetext{
* SME - Secretaria Municipal de Educação. Bom Jardim - PE - Brasil. 55730-000 - elida.ferreira@ yahoo.com.br

** UEPB - Universidade Estadual da Paraíba. Centro de Educação - Pós-graduação em Formação de Professores. Campina Grande - PB - Brasil. 58429-500. UFPE - Universidade Federal de Pernambuco. Centro Acadêmico do Agreste - Pós-graduação em Educaçáo Contemporânea. Campina Grande - PB Brasil. 58424-210 - fabiohispanista@gmail.com
} 
modelo/formato tecnológico, os quais podem ser bastante promissores para o cenário educacional e, em especial, para o processo de ensino-aprendizagem de línguas adicionais, nosso interesse maior para reflexão neste texto.

Conforme apresentado em Souza (2015a), utilizaremos, ao longo deste texto, o termo adicionais, e não estrangeiras, ao fazer referência às línguas não maternas porque consideramos que o termo estrangeiro tem conotaçóes que remetem ao que é alheio, diferente, oposto.

Compartilhando da citação de Almeida Filho (1993, p. 15) de que aprender Língua Estrangeira "é crescer numa matriz de relações interativas na língua-alvo que gradualmente se desestrangeiriza para quem a aprende (destaques nossos)" e, tendo em vista que a língua, para ser aprendida/adquirida ${ }^{1}$ precisa se desestrangeirizar num complexo contínuo, julgamos mais adequado nomeá-la como uma língua adicional, e não estrangeira.

Voltando à temática do papel das TDICs na mediação de processos colaborativos de ensino-aprendizagem, para que as pessoas possam usufruir dos recursos provenientes desses eventos tecnológicos faz-se necessária a apropriação instrumental, linguística e sociocultural concernente a esse meio. Cercado por diversos aparatos, quando o aprendiz consegue conhecê-los, ou pelo menos, usar alguns de seus muitos atributos na posição de autor e leitor crítico, adquire características do letramento digital e, dessa forma, desenvolve o processo de ensino-aprendizagem com engajamento e colaboraçáo.

Dentro desse viés, reconhecemos a necessidade de que os aprendizes, em um contexto colaborativo de ensino-aprendizagem de línguas, possam lançar mão dos recursos audiovisuais disponíveis na internet para mediar práticas de teletandem, as quais acontecem quando duplas colaborativas se unem em prol da aprendizagem mútua. $\mathrm{E}$, mais especificamente, quando pares pertencentes a culturas e línguas diferentes se relacionam com o objetivo de ensinar a sua língua e aprender a língua do outro, o que implica também na influência cultural entre os participantes desse processo.

Em virtude desse pensamento, objetivamos refletir sobre a influência do letramento digital no que diz respeito ao uso dos recursos audiovisuais virtuais em prol da mediação pedagógica no âmbito do teletandem.

Para melhor organização das ideias, iniciaremos apresentando as características da aprendizagem em tandem, suas nuances e filiação metodológica, assim como evidenciaremos o projeto institucional Teletandem $\mathrm{UEPB}^{2}$ como ponte para o ensino de línguas adicionais, além de situarmos suas características e objeçóes no contexto intercultural e linguístico de ensino-aprendizagem de língua portuguesa e espanhola como línguas adicionais no contexto da integração latino-americana.

\footnotetext{
Os termos aquisiçáo e aprendizagem serão utilizados neste texto indistintamente, apesar de sabermos das discussóes em torno desta temática, bem como da dicotomia estabelecida por Krashen (1982).

2 Universidade Estadual da Paraíba.
} 
Em seguida, refletiremos a respeito da relevância da inserção dos recursos audiovisuais virtuais como mecanismos didáticos para o desenvolvimento de competências linguísticoculturais no contexto de ensino-aprendizagem de línguas por pares interagentes; na sequência, apresentaremos as influências do letramento digital no contexto educacional contemporâneo, sua relação com as TDICs, sua dimensão multimodal, intersemiótica, crítica e sociocultural e sua relação com o audiovisual nos processos de ensinoaprendizagem de línguas mediados pelas TDICs; e, por fim, faremos uma reflexão sobre algumas atividades realizadas dentro do projeto Teletandem UEPB que envolvem audiovisual, letramento digital, TDICs e ensino de línguas, além de incentivarmos a necessidade de pesquisas que envolvam a temática em estudo.

\section{Teletandem: um mecanismo para viabilização do processo de ensino- aprendizagem de línguas por meios das TDICs}

A partir de uma consistente revisão bibliográfica, Benedetti (2010) apresenta que, embora ainda pouco conhecida no Brasil, a aprendizagem de línguas em tandem surgiu na Alemanha no final dos anos 1960, tendo se disseminado nas décadas seguintes a outros países da Europa como uma modalidade alternativa e complementar à aprendizagem formal de línguas adicionais (SOUZA, 2015b).

Inicialmente, o termo tandem fazia referência a uma bicicleta para duas pessoas, que se sentam uma atrás da outra e que tem pedal para ambos. Com o passar do tempo, este termo também passou a ser utilizado para definir um conjunto de duas pessoas que tem uma atividade comum ou que colaboram em algo. No campo do ensinoaprendizagem de línguas, "[...] a aprendizagem em tandem consiste no intercâmbio e compartilhamento de conhecimento entre indivíduos de culturas diferentes, com propósitos de aprendizagem de línguas de modo colaborativo." (BENEDETTI, 2010, p. 21).

Esta prática está baseada na concepção sociocultural do desenvolvimento humano e concebe, portanto, a aprendizagem como processual e socialmente mediada que fomenta a constituição de parcerias entre pessoas que desejam aprender uma língua adicional e concordam em atingir essa meta por meio de práticas com falantes proficientes no idioma que se deseja aprender.

Resumidamente, aprendizagem em tandem significa provimento recíproco de apoio e instrução entre dois aprendizes, onde cada um deles é falante nativo (ou proficiente) na língua-alvo do outro que se realiza presencialmente ou mediante outro meio de comunicação. (BENEDETTI, 2010, p. 22).

São características da aprendizagem em tandem: i) aberta, já que não segue um programa curricular fixo; ii) intercultural, pelo fato de envolver diferentes línguas e culturas; iii) interpessoal, praticada por pares de aprendizes; iv) socialmente simétrica, 
envolve a alternância de papéis, já que num momento se é aprendiz da língua do outro e, noutro, professor do seu próprio idioma.

Dito com outras palavras, a aprendizagem em tandem pode ser definida como um processo em que colaboram duas pessoas com diferentes línguas maternas; se ajudam mutuamente trabalhando para melhorar os conhecimentos idiomáticos, culturais e, às vezes, também para intercambiar outro tipo de informação relacionada, por exemplo, a seus respectivos estudos, gostos ou áreas de interesse ou trabalho.

$\mathrm{O}$ trabalho em tandem pode ser realizado em diferentes perspectivas:

- Presencial - chamado também face a face. A comunicação é predominantemente oral, porém os participantes podem recorrer, sempre que queiram, a materiais escritos e também podem fazer anotaçóes.

- Por correio eletrônico (e-mail) - Conhecido também por e-tandem. Levando em conta que os participantes em e-tandem se encontram em lugares diferentes, é difícil organizá-lo seguindo as mesmas pautas que no tandem presencial.

- Teletandem - Diferencia-se do tandem presencial e do e-tandem por permitir uma interação completa (escrita, áudio e vídeo) em tempo real entre os participantes, devido a alguns programas de comunicação gratuitos através da internet (RAMMÉ; OLMO, 2014).

Independente da perspectiva adotada, trata-se de uma possibilidade para comunicação autêntica na língua-alvo. Neste contexto, as informaçóes negociadas a respeito da cultura, da forma de vida, dentre outros elementos de determinado país, provêm de uma pessoa concreta, com sua personalidade e percepção do que está a sua volta.

É um complemento para a aula de língua adicional, tanto se for realizado de forma presencial como pela internet. Aprender em tandem é uma prática realizada por meio de comunicaçáo autêntica com um interlocutor nativo ou com um bom nível de proficiência na língua-alvo, que serve de modelo e que pode corrigir e auxiliar na hora de expressar-se.

Em sua concepção atual e em suas muitas formas (em duplas, em grupos, em e-tandem, tandem face a face, teletandem, etc), o tandem tornou-se, antes de tudo, uma atividade complementar ao processo tradicional de aprendizagem de línguas (em sala de aula, principalmente), pois coloca os aprendizes de língua estrangeira em contato com falantes nativos da língua alvo, propiciando assim ambientes comunicativos autênticos onde estes podem desenvolver suas habilidades sociocognitivas, interculturais e linguísticas de maneira plena e irrestrita. (RAMMÉ; OLMO, 2014, p. 4).

O fato de que ambos podem, de alguma forma, falar a língua do outro, permitelhes que possam se ajudar mutuamente mediante explicaçóes, comparaçóes entre as culturas ou os esquemas linguísticos. Além disso, ao estabelecer-se uma comunicação 
entre pessoas de diferentes comunidades de línguas e de culturas, facilita-se, igualmente, a aprendizagem intercultural.

O tandem, como ferramenta de aprendizagem de uma língua estrangeira, pode ser enquadrado nas mais recentes teorias sócio interacionistas de ensino-aprendizagem. Vygotsky e Bakhtin, ao colocarem a cultura e a linguagem na constituição social do sujeito e do conhecimento influenciaram fortemente o ensino de LE. Para ambos, a língua é produto de atividades sociais, resultantes de interações entre interlocutores, portanto, o ensino de LE náo pode deixar de considerar a língua em contexto. Em consonância, o tandem baseia-se no pressuposto de que nas interaçóes entre os tandenistas 'o conhecimento (da língua, da cultura, do outro) é socialmente coconstruído na interação entre os parceiros por meio da linguagem’. (RAMMÉ; OLMO, 2014, p.-5).

O desenvolvimento da alteridade e da competência intercultural ${ }^{3}$ se apresenta como um fator importante com a mediação tecnológica. Sempre fez parte da aprendizagem de línguas, no entanto, atualmente tem adquirido uma crescente importância.

\section{Projeto Teletandem UEPB: algumas considerações}

Dentro desse viés, podemos refletir em relação ao projeto interinstitucional "TELETANDEM UEPB", atividade colaborativa entre a Universidade Estadual da Paraíba (campus de Monteiro e Campina Grande), Universidade Federal de Pernambuco (campus de Caruaru), Instituto Federal da Paraíba (campus de Monteiro), Universidade Federal da Integração Latino-Americana e do Instituto de Idiomas de Salta ${ }^{4}$ (Argentina).

A proposta, em andamento desde 2014, visa fomentar o intercâmbio linguísticocultural entre os alunos em português e espanhol como línguas adicionais, vem sendo desenvolvida como projeto de extensão e compreende o linguístico como elemento fundamental no processo de integração regional e, dessa forma, o espanhol e o português são pensados como línguas adicionais multidimensionais e interculturais

\footnotetext{
3 Compreenderemos, neste texto, a competência intercultural como "[...] a capacidade de perceber, usando-se de todos os mecanismos disponíveis, a diversidade do outro, e sendo capaz de dominar seus sentimentos pessoais, de neutralizar suas crenças e de pensar de forma a poder se colocar no lugar do outro" (SALOMÃO, 2012, p.108). Compartilhamos da visão de Byram (1997), que apresenta o modelo de competência comunicativa intercultural sendo composto pela competência linguística, competência sociolinguística, competência discursiva e competência intercultural. Para o pesquisador, a competência intercultural abarcaria savoir comprende (interpretar), savoir faire (descoberta/habilidades de interação), savoir (conhecimento - de si próprio e dos outros), savoir s'engager (consciência cultural crítica) e savoir être (atitudes).

4 Parceria mediada pela Profa. Liliana Roxana Rubín. Instituto de idiomas de Salta n. ${ }^{\text {o }}$ 7216, mantido pela gestão pública de educação não formal do Ministério da Educaçáo.
} 
de forma a promover uma integração que considere a América Latina como uma construção cultural, histórica, política e não somente uma construção geográfica (SOUZA, 2014).

\section{Os recursos audiovisuais disponíveis em rede como mediadores da potencialização do processo de ensino-aprendizagem de línguas}

Os recursos audiovisuais virtuais são artefatos tecnológicos de incontestável importância para o processo de ensino-aprendizagem mediado pelas TDICs, no contexto do teletandem, uma vez que permitem a interação linguística dos interagentes de línguas adicionais de maneira mais dinâmica e atrativa, além de permitir mostrar e compartilhar com o parceiro elementos culturais de seu país.

Segundo Rojo (2010), a educação linguística deve apreciar, no contexto das práticas sociais de leitura e escrita, dentre outros letramentos (críticos, múltiplos), os letramentos multissemióticos pela necessidade que as pessoas têm de lidar com a diversidade de textos contemporâneos que envolvem múltiplos meios semióticos, por conta das tecnologias vigentes.

Para Rojo (2010, p. 437), os letramentos multissemióticos correspondem à capacidade que a pessoa tem de ampliar "[...] a noção de letramento para o campo da imagem, da música, das outras semioses que não somente a escrita." Este tipo de letramento exige que a pessoa saiba ler e compreender os textos compostos por muitas linguagens, ou seja, além de se apropriar das múltiplas linguagens que o texto oferece, o leitor e produtor textual deve saber articulá-las em prol de dar significado ao texto lido ou produzido.

Dentro desse contexto, podemos evidenciar os recursos audiovisuais disponíveis na sociedade com toda gama semiótica que os compóem, os quais cobram de seus consumidores e produtores o letramento multissemiótico. Destarte, partilhamos das ideias de Coutinho (2006) de que o audiovisual ou a linguagem audiovisual dispóe dos elementos sonoros e visuais e envolve elementos culturais, como também surge da realidade e proporciona uma compreensão acerca do mundo.

A partir dessa concepção ampla da qual tratamos as produçóes audiovisuais, nosso interesse maior se situa na variedade destes recursos disponíveis no âmbito virtual e que em muito podem contribuir como recurso didático consciente para o processo de ensino-aprendizagem de línguas adicionais, mediado pelas TDICs, numa dimensão linguística, cultural e intercultural.

De acordo com Souza (2014, p. 156), "O audiovisual é a linguagem do principal meio de comunicaçáo social e tem presença marcante na produção cultural contemporânea, o que pode ser observado desde a propaganda até a sofisticada produção cinematográfica contemporânea." Para o autor, há uma diversidade de gêneros que fazem uso da linguagem audiovisual nos dias de hoje e a internet é revolucionária no que diz respeito à sua produção e circulação. 
Desta forma, em observância ao processo educativo de ensino de línguas por pares interagentes no contexto do teletandem, entendemos por possíveis recursos didáticos audiovisuais: noticiários, comerciais, propagandas, vinhetas, documentários, programas, vídeos, jogos, videoconferência, videoaula, cinema, narrativas seriadas, tutoriais, videoclipe, curta metragem, recitais, dentre tantos outros que utilizem, em sua composição e apresentação, imagem e som, concomitantemente, além de que possam ser compartilhados, analisados, estudados, selecionados e/ou produzidos pelos estudantes de línguas no contexto supramencionado.

Kollas e Boff (2014), parafraseando Arroio e Giordan (2006) afirmam que “[...] o recurso audiovisual é uma produção cultural, pois ele é uma codificação da realidade, quem produz esse material está tentando reproduzir uma descrição dessa realidade e, para isso, utiliza símbolos da cultura para o público que será direcionado." (KOLLAS; BOFF, 2014). Por isso, defendemos as potencialidades dos audiovisuais para além do linguístico, numa dimensão cultural, o que propóe ao aprendiz de línguas ter a possibilidade de entrar em contato com os aspectos culturais da língua-alvo.

A partir de uma pesquisa bibliográfica realizada sobre a contribuição da produção de material didático audiovisual para a formação docente, Kollas e Boff (2014) chegaram a conclusão que os recursos audiovisuais, na dimensão da produção de material didático, incentivam a aprendizagem através da pesquisa, problematiza conceitos de complexo entendimento de forma prazerosa, possibilita um trabalho interdisciplinar por aproximar as diversas áreas do conhecimento, além de que "[...] o material produzido pode ser compartilhado para debates entre diferentes estudantes, pesquisadores e professores." (KOLLAS; BOFF, 2014).

Ainda sobre as potencialidades dos recursos audiovisuais para o ensino de línguas, Garcia-Stefani (2015), por meio de uma apurada revisão bibliográfica, ao abordar o cinema como mediador do processo de ensino e aprendizagem de inglês e espanhol na formação continuada de professores de línguas, enfatiza quinze vantagens para a utilização deste recurso audiovisual, são elas: material didático autêntico; material lúdico; elemento contextualizador da $\mathrm{LE}^{5}$; agente motivador do aprendizado; fomentador do trabalho com as $\mathrm{TICs}^{6}$ em sala de aula; estímulo para pesquisa extraclasse; forma inovadora de ensinar; fonte de percepção de diferentes linguagens; vitrine de situaçóes verossímeis de comunicação; encorajador do uso da língua-alvo; facilitador do desenvolvimento de habilidades linguístico-culturais; propulsor do desenvolvimento da autonomia na aquisição da LE; veículo para trabalhar interdisciplinaridade; facilitador da compreensão de mundo; e, por fim, ferramenta na formação crítica de professores de línguas.

Souza (2014) nos assegura que a internet possibilitou ao usuário não apenas o consumo do material audiovisual disponível, mas também a sua posição de autoria.

Língua estrangeira.

6 Tecnologias de Informação e Comunicação. 
Ainda nos alerta sobre a necessidade de um posicionamento do usuário diante da diversidade de recursos que a teia de alcance mundial nos permite ter acesso, o que exige do espectador "[...] compreender os vários discursos presentes nos produtos culturais transmitidos pela mídia" (SOUZA, 2014, p.156).

Em consonância com o posicionamento de Souza (2014), em estudos sobre letramentos multimidiáticos e suas relaçóes semióticas, Lemke (2010, p. 463) esclarece que "[...] tanto as habilidades de autoria, quanto as habilidades críticas e interpretativas voltadas à multimídia transformam potencialmente não apenas a forma como estudantes e professores comunicam suas ideias, mas também as formas como aprendem e ensinam".

\section{O letramento digital e sua relevância para o cenário educacional virtual}

Para que o processo de ensino-aprendizagem possa acontecer no âmbito virtual, ou melhor, através dos recursos que esse campo oferece, faz-se necessário levarmos em consideração a apropriação das técnicas, habilidades e linguagens concernentes a esse meio, pelo público que dele participa, para o desenvolvimento das múltiplas formas de aprendizagem.

Nesse viés, podemos pensar no letramento digital - capacidade de compreender e produzir textos no universo digital, além de interagir no mundo virtual - como um fator primordial para o processo de ensino e aprendizagem mediado pelas TDICs, uma vez que a apropriação desse letramento converge para o bom desempenho do participante durante o complexo processo de aquisição, troca, interação e compartilhamento de aprendizagens no universo virtual.

Para Xavier (2007), o letramento digital circunda numa dimensão não apenas a nível educacional, mas de sobrevivência. $\mathrm{O}$ autor assim o reconhece por compreender a dimensão social própria desse tipo de letramento. Ao passo que, de acordo com Buzato (2009), letramento digital pode ser compreendido como uma questão de inclusão digital, posto que não se limita ao manuseio de equipamentos, mas circula no patamar de uso, transformação e aplicação das tecnologias de informação e comunicação em prol de interesses sociais e pessoais.

Em confirmação ao anteriormente exposto, Azevedo e Gasque (2012) sinalizam o letramento digital em favor do desenvolvimento humano. Para as autoras, este letramento "[...] acompanha a evolução dos contextos tecnológico, econômico, social, cultural e político de uma dada sociedade." (AZEVEDO; GASQUE, 2012). Portanto, advém das presunções, anseios e objetivos das pessoas que compóem a sociedade atual.

Outro ponto evidenciado pelas autoras condiz ao fato de as experiências sinestésicas serem apresentadas como característica relevante do letramento digital. Para elas,

No ambiente colaborativo do hipertexto, os arranjos textuais, as imagens, os sons e as animaçóes permitem ao sujeito vivenciar situaçôes que estimulam o pensamento, os sentimentos, os anseios, os sonhos... Nos novos espaços, percebidos subjetivamente, 
ocorrem diálogos que podem superar preconceitos e diferenças, além de instigar a curiosidade e o espírito investigativo. (AZEVEDO; GASQUE, 2012).

Nessa vertente de pensamento, podemos pensar que para que práticas de ensino e aprendizagem de línguas com o uso dos recursos audiovisuais presentes no mundo virtual possam ser desempenhadas com qualidade, faz-se necessário que os participantes de atividades nesse meio se apropriem de funçóes diversas no campo do letramento digital. Segundo pesquisas como a de Telles e Maroti (2008), quando não conseguem lidar com práticas de letramento digital, os participantes de práticas de teletandem ficam desestimulados, sofrem com a incompatibilidade de escolha de equipamentos utilizados entre as duplas, podendo chegar à desistência.

\section{Ressignificando conceitos e papéis no âmbito das TDICs e do letramento digital}

As TDICs, atualmente, são caminhos bastante apreciados no universo do processo de ensino e aprendizagem. Isso advém das potencialidades por elas permitidas para que a construção de aprendizagens exceda o espaço escolar, uma vez que estas ferramentas estão presentes no cotidiano das pessoas (DEMO, 2011) e são elementos essenciais para o campo pedagógico (KENSKI, 2007).

Essas tecnologias quando "[...] desenvolvidas preponderantemente em ambientes colaborativos, permitem ao sujeito passar de um indivíduo pensante para integrar uma ecologia cognitiva, que inclui as mentes humanas e as redes técnicas de armazenamento, de transformação e de partilha das representaçóes." (AZEVEDO; GASQUE, 2012).

Dentro dessa perspectiva, podemos refletir sobre o potencial colaborativo e integrado permitido pelas TDICs, uma vez que abre fronteiras e possibilidades para que as pessoas possam desenvolver competências para além da individualidade, mesmo que separadas pela distância espacial, pelas relaçôes culturais, ideológicas, dentre tantas outras categorias que diferenciam os seres humanos.

Dessa discussão advém a relação das TDICs com o letramento digital, uma vez que, para usufruir dos benefícios propostos por aquelas faz-se essencial adquirir as características deste, as quais podem ser resumidas pela seguinte afirmação:

[...] conjunto de competências necessárias para que um indivíduo entenda e use a informação de maneira crítica e estratégica, em formatos múltiplos, vinda de variadas fontes e apresentada por meio do computador, de maneira crítica e estratégica, sendo capaz de atingir seus objetivos, muitas vezes compartilhados social e culturalmente. (FREITAS, 2010, p.339-340).

Nesta mesma linha de pensamento sobre o letramento digital, podemos nos ancorar na definição apresentada por Buzato (2009, p.21) “[...] redes complexas e heterogêneas 
que conectam letramentos (práticas sociais), textos, sujeitos, meios e habilidades que se agenciam, entrelaçam, contestam e modificam mútua e continuamente, por meio, virtude ou influência das TIC".

Em se tratando da necessidade de mudança da postura do sujeito, o qual não mais pode ser acrítico, muito pelo contrário, precisa atuar socialmente, enquanto cidadáo, que indaga, propóe e produz, Xavier (2007) apresenta as competências próprias que requer o letramento digital. De acordo com o autor,

O letramento digital requer que o sujeito assuma uma nova maneira de realizar as atividades de leitura e de escrita, que pedem diferentes abordagens pedagógicas que ultrapassam os limites físicos das instituiçôes de ensino, em vários aspectos, especialmente no que diz respeito a: velocidade do próprio ato de apreender, gerenciar e compartilhar as informaçôes; verificação on-line pela Internet da autenticidade das informaçôes apresentadas, com condiçâo de comprovar ou corrigir os dados expostos virtualmente em um site da grande rede; ampliação do dimensionamento da significação das palavras, imagens e sons por onde chegam as informaçóes a serem processadas na mente do aprendiz; crescimento da participação de outros interlocutores na "composição coletiva" e, às vezes, simultânea de textos na Internet. (XAVIER, 2007, p.138).

Dentro desse contexto, podemos refletir também sobre o papel do professor enquanto mediador de processos de ensino e aprendizagem no meio virtual, uma vez que este tem papel fundamental no desenvolvimento de competências por parte dos estudantes.

Pesquisas como a de Kenski (2007) apontam a dificuldade dos professores em mediar processos de ensino e aprendizagem por meio das TDICs. A dificuldade mais enfática demonstrada pelos docentes pauta-se na complexidade em elaborar atividades significativas, de acordo com as características do público e do conteúdo em questão, com o aparato das tecnologias digitais. Todavia, conforme Marzari e Leffa (2013, p.4), quando letrado digital, o professor " [....] (re)conhece os recursos tecnológicos que estáo a sua disposição, durante sua atuação didático-pedagógica, mas principalmente se apropria deles, utilizando-os de forma coerente, reflexiva e criativa."

Nessa relação entre TDICs, letramento digital, papel do professor e do aprendente, podemos elucidar esses papéis na dimensão do audiovisual e do contexto teletandem. Isso reporta ao interagente aprendiz de línguas, no contexto do qual tratamos, a necessidade de atuar como mediando-mediador, por conta da troca de papéis quando ensina e aprende línguas, o que implica a sua precisáo de apropriar-se do letramento digital em dupla complexidade: atuando e mediando. Esse universo requer criticidade para o processo de escolhas e produçáo, e, por isso, exige competências do letramento digital crítico, sobre o qual trataremos a seguir. 


\section{Letramento digital crítico e sua influência nas competências desempenhadas no campo audiovisual dentro da proposta teletandem}

Diante das várias possibilidades intersemióticas dos textos/hipertextos e de suas viabilizaçóes no meio virtual, em especial, no que tange às nuances trazidas pelos recursos audiovisuais (recepção, manipulação, seleção, transformação e produção) como caminhos viáveis para o ensino de línguas por meio das TDICs, em particular, nas dimensões do teletandem, enxergamos a necessidade de uma breve discussão sobre o letramento digital numa perspectiva crítica.

A partir dessa ideia, Lemke (2010) nos apresenta a possibilidade de nos perdemos no ciberespaço ${ }^{7}$. Para este autor, "O letramento promove tanto o poder quanto a vulnerabilidade” (LEMKE, 2010, p. 475), além de tecer uma indagação sobre o letramento e as escolhas sábias. Pois bem, o mundo virtual nos permite ter contato com uma infinidade de informaçóes, elementos semióticos, audiovisuais etc., e para que saibamos usá-los em nosso favor, precisamos ter discernimento para fazermos as escolhas necessárias.

Ao tratar sobre a educação linguística na contemporaneidade, Rojo (2010) ressalta como essenciais, dentre outros letramentos (multiletramentos, letramentos semióticos), os letramentos críticos e protagonistas, elucidando a necessidade da ética e do posicionamento das pessoas no que diz respeito ao volumoso número de textos difundidos na sociedade.

Nessa mesma direção, Buzato (2009) ao abordar as relações entre inclusão, tecnologia e letramento digital, defende a articulação deste com o letramento crítico, uma vez que entende a importância da criticidade no campo digital para dissipar as relaçóes de poder assimétricas presentes na sociedade, assim como persiste na ideia da transformação do sujeito social com o apoio do letramento numa perspectiva crítica.

Em síntese ao discutido sobre letramento digital crítico, Saito e Souza (2011, p.136) pluralizam o termo e o definem,

Letramento(s) Digital(is) críticos, [...] são letramentos que se dão em vários meios digitais e que preocupam-se com a tomada de posição crítica do usuário frente aos textos que pesquisa, lê, produz, comenta em ambientes digitais; sua consciência das ferramentas e várias semioses para construção de sentido, sempre situado e intencional; sua compreensão e adequação às práticas discursivas do meio digital, que se manifestam através de vários gêneros emergentes (e-mail, blog, comments, scrap, etc.); a reflexão sobre suas açóes e interaçôes, assim como seu compromisso ético nas práticas digitais; sua tomada de poder: 1) ao estabelecer uma identidade

\footnotetext{
O termo especifica não apenas a infra-estrutura material da comunicação digital, mas também o universo oceânico de informaçôes que ela abriga, assim como os seres humanos que navegam e alimentam esse universo (LÉVY, 1999, p. 17).
} 
plena de crenças, ideologia, determinada em relação com a alteridade; 2) ao exercer a criticidade e a cidadania em ambiente digital.

Desta maneira, entendemos que, diante de um turbilhão de informaçóes pertencentes ao campo audiovisual no âmbito da internet, para que os aprendentes e mediadores, isto é, os participantes das práticas de teletandem, possam desempenhar significativas atividades de ensino e aprendizagem neste universo, precisarão desempenhar competências críticas no campo do letramento digital.

\section{Algumas reflexões...}

Ao longo deste texto, nos dedicamos a abordar as relaçóes entre uma promissora proposta de ensino-aprendizagem de línguas mediada pelas TDICs, o teletandem; a inserção dos recursos audiovisuais disponíveis no campo virtual como recursos didáticos nesse processo; assim como a necessidade de os pares interagentes dessa proposta adquirirem as competências requeridas pelo letramento em prol de realizarem atividades de recepção, manipulação, seleção, transformação e produção de elementos audiovisuais em nível proficiente.

Nesse ínterim, faz-se interessante ressaltarmos algumas ideias sobre as discussóes antes apresentadas. Inicialmente, é de significativa relevância apresentarmos o teletandem enquanto caminho potencializador dos elementos audiovisuais por meio das TDICs, tendo em vista que, dentro das propostas de tandem, o teletandem é o que se constitui com maior agregação desses elementos por ser uma proposta possível de ser realizada com o atributo da internet e de alguns programas de comunicação gratuitos, além de possibilitar o trabalho conjunto das habilidades básicas, simultâneas e complementares de leitura, escrita, audição e expressão oral, acopladas ao áudio e vídeo, características inerentes aos audiovisuais.

No que diz respeito ao projeto Teletandem UEPB, constatamos que o audiovisual já agrega as suas dimensôes práticas, com impactos positivos, tanto no que acomete à produção audiovisual quanto no que faz referência à seleção/manipulação desses elementos, o que indica a presença de competências do letramento digital nesse meio.

Em se tratando da produção audiovisual e do desenvolvimento da competência de autoria do letramento digital, podemos mencionar a produção de vídeos pelos interagentes, tanto na língua nativa quanto na língua-alvo, que foram postados em um grupo secreto no facebook com o propósito da formação de duplas. A exemplo dessa atividade, podemos apresentar a seguinte imagem: 
Imagem 1 - Tela inicial do vídeo de apresentação da Nathália gravado em espanhol-língua adicional para participação no projeto "Teletandem UEPB”.

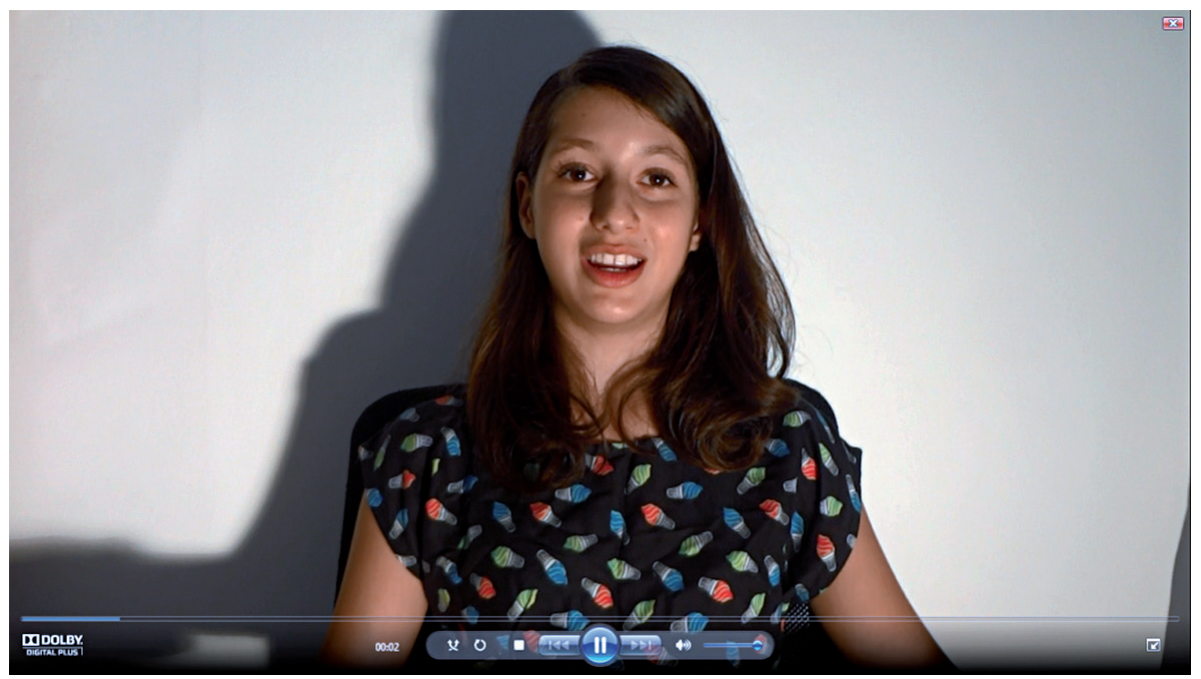

Fonte: Corpus reunido no desenvolvimento do projeto "Teletandem UEPB".

No que condiz à manipulação/seleção e potencialidades dos audiovisuais, assim como ao desenvolvimento de competências de letramento digital intersemiótico, sociocultural e crítico, como também potencial das TDICs, podemos apresentar o seguinte excerto, advindo das consideraçóes de uma interagente argentina que participa do projeto Teletandem UEPB:

O potencial das TDICs nos permite estar conectados em tempo real, fazer chamadas de vídeo, ouvir ao outro e fazer com que nos escute. As ferramentas da internet também nos permitem fazer o uso de material audiovisual (no meu caso, encontro um grande potencial nos vídeos, poemas falados, filmes, entre outros). Essas ferramentas ajudam no processo de aprendizagem e nos permitem conhecer o outro de uma forma mais dinâmica. Por exemplo, com Janice trocamos filmes nacionais... Ela sugeriu um filme brasileiro e eu, um argentino. Por meio destas produçóes de cinema, podemos ir aprendendo da cultura do país vizinho, podemos nos apropriarmos das expressóes idiomáticas e ver belas paisagens, captadas pela câmara. (Relato da Dafne) ${ }^{8}$.

\footnotetext{
8 Nossa tradução para: "El potencial de las TDICs nos permite estar conectados en tiempo real, realizar video llamadas, escuchar al otro y hacer que nos escuchen. Las herramientas de Internet nos permiten además hacer uso de material audiovisual (en mi caso encuentro un gran potencial en los videos, los poemas hablados, las peliculas, entre otros). Estas herramientas ayudan en el proceso de aprendizaje y nos permiten conocer al otro de una manera más dinámica. Por ejemplo, con Janice intercambiamos películas nacionales... Ella me sugirió una pelicula brasilera y yo, una argentina. A través de esas producciones cinematográficas uno puede ir
} 
Como pudemos vislumbrar ao longo dessa discussão, o ensino-aprendizagem de línguas mediado pelas TDICs, num contexto colaborativo (teletandem), pode ser potencializado pelos diversos recursos audiovisuais disponíveis no meio virtual e produzidos pelos próprios interagentes, desde que estes dominem competências características do letramento digital em suas variadas nuances, dentre elas, semiótica, sociocultural, crítica e técnica. O projeto Teletandem UEPB, nos dá exemplos dessa positividade.

Mediados pelo propósito de não esgotar a discussão e compreendendo a proposta que articula recurso audiovisual, TDICs, ensino-aprendizagem de línguas, teletandem e letramento digital, vislumbramos a necessidade de outros estudos que evidenciem este modo de mediar o desenvolvimento de competências linguísticas, culturais e interculturais num fazer que ultrapassa os ditames da mera singularidade artificial do ensino unidirecional e estrangeiriço, próprio do ensino tradicional de línguas.

\section{DIGITAL LITERACY AND AUDIOVISUAL, IMPROVERS OF COLLABORATIVE LEARNING OF PORTUGUESE AND SPANISH AS ADDITIONAL LANGUAGES}

- ABSTRACT: This study aims to discuss digital literacy and audiovisual resources as improvers of Portuguese and Spanish collaborative learning as additional languages. Digital information and communication technologies are very promising paths to the educational field and in particular for language teaching from a linguistic-cultural point of view. In this bias, we can observe the teletandem as an improver instrument of actual authentic practices concerning the contact with languages, in a cross-cultural universe. Therefore, we recognize the importance of digital literacy and audiovisual resources to promote the teaching-learning process, among other things, by improving the linguistic-cultural authenticity suggested by teletandem. Thus, we observe, in this discussion, that when students have full knowledge of skills inherent to digital literacy, they successfully make use of audiovisual resources and ensure good results in the acquisition of languages, which can be proved by practices carried out in the context of institutional Teletandem.

- KEYWORDS: Digital literacy. Audiovisual resources. Teaching and learning languages. ITs. Teletandem.

aprendiendo de la cultura del pais vecino, puede apropiarse de las expresiones idiomáticas y observar paisajes hermosos, captados por la cámara." (Relato da Dafne). 


\section{REFERÊNCIAS}

ALMEIDA FILHO, J. C. P. Dimensóes comunicativas no ensino de línguas. Campinas: Pontes, 1993.

AZEVEDO, I. C. M.; GASQUE, K. C. G. D. Contribuiçóes do letramento digital e informacional na emancipaçáo humana. 2012. Disponível em: <http://maristaonline.org.br/ literacia/wp-content/uploads/2012/06/Contribuicoes-do-letramento-digital-e-informacional_ Isabel-Azevedo-e-Kelley-Gasque.pdf>. Acesso em: 15 abr. 2013.

BENEDETTI, A. M. Dos princípios de tandem ao teletandem. In: BENEDETTI, A. M.; CONSOlO, D. A.; VIEIRA-ABRAHĀO, M. H. (Org.). Pesquisas em ensino e aprendizagem no Teletandem Brasil: línguas estrangeiras para todos. Campinas: Pontes, 2010. v.1. p.21-46.

BYRAM, M. Teaching and assessing intercultural communicative competence. Clevedon: Multilingual Matters, 1997.

BUZATO, M. K. Letramento e inclusão: do estado-nação à era das TIC. DELTA, São Paulo, v.25, n.1, p.1-38, 2009.

COUTINHO, L. M. Audiovisuais: arte, técnica e linguagem. Brasília: Ed. da UnB, 2006.

DEMO, P. Olhar do educador e novas tecnologias. Boletim Técnico do Senac, Rio de Janeiro, v.37, n.2, p.15-26, maio/ago. 2011.

FREITAS, M. T. Letramento digital e formação de professores. Educaçáo em Revista, Belo Horizonte, v. 26, n. 3, p.335-352, 2010.

GARCIA-DE-STEFANI, V. C. Formaçáo continuada de professores de línguas estrangeiras mediada pelo cinema: contribuiçóes da teoria da atividade. 2015. 284f. Tese (Doutorado em Linguística) - Universidade Federal de São Carlos, São Carlos, 2015.

KENSKI, V. M. Educação e tecnologias: o novo ritmo da informação. 2. ed. Campinas: Papirus, 2007.

KOLLAS, F; BOFF, E. T. O. Compreensôes sobre a produção e uso de material didático audiovisual na formação docente. In: JORNADA DE PESQUISA, 19., 2014, Santa Rosa. Anais... Santa Rosa: Unijuí, 2014. Disponível em: <https://www.revistas.unijui.edu.br/index. php/salaoconhecimento/article/viewFile/3711/3098>. Acesso em: 20 dez. 2015.

KRASHEN, S. D. Principles and practice in second language acquisition. New York: Pergamon, 1982.

LEMKE, J. L. Letramento metamidiático: transformando significados e mídias. Tradução de Clara Dornelles. Trabalhos em Linguística Aplicada, Campinas, v.49, n.2, p.455-479, jul./ dez. 2010. 
LÉVY, P. Cibercultura. Tradução de Carlos Irineu da Costa. São Paulo: 34, 1999. (Coleção TRANS).

MARZARI, G. Q.; LEFFA, V. J. O letramento digital no processo de formação de professores de línguas. Tear: Revista de Educaçáo Ciência e Tecnologia, Canoas, v.2, n.2, p.1-18, 2013.

RAMMÉ, V.; OLMO, F. C. del. Tandem: guia para uma aprendizagem solidária. Curitiba, 2014. Disponível em: <http://pt.slideshare.net/ValRamm/manual-tandem-unila-pb-versao-1>. Acesso em: 14 fev. 2015.

ROJO, R. H. R. Letramentos escolares: coletâneas de textos nos livros didáticos de língua portuguesa. Perspectiva, Florianópolis, v.28, n.2, p.433-465, jul./dez. 2010.

SAITO, F. S.; SOUZA, P. N. (Multi)letramento(s) digital(is): por uma revisão de literatura crítica. Linguagens e Diálogos, [Rio de Janeiro], v.2, n.1, p.109-143, 2011.

SALOMÃO, A. C. B. A cultura e o ensino de língua estrangeira: perspectivas para a formação continuada no projeto Teletandem Brasil. 269f. 2012. Tese (Doutorado em Estudos Linguísticos) - Universidade Estadual Paulista "Julio de Mesquita Filho", São José do Rio Preto, 2012.

SOUZA, F. M. A sétima arte como artefato semiótico mediador das reflexóes a respeito de como se aprende uma língua adicional. Revista Hispanista (Edição em Português), Rio de Janeiro, v.16, n.63, p.1-12, 2015 a.

SOUZA, F. M. Teletandem UEPB. Campina Grande: PROEX/UEPB, 2015b. Projeto de Extensão.

SOUZA, F. M. O cinema como mediador na (re)construçáo de crenças de professores de espanhol-língua estrangeira em formaçáo inicial. 284f. 2014. Tese (Doutorado em Educação: Cultura, Organização e Educação) - Faculdade de Educação, Universidade de São Paulo, São Paulo, 2014.

TELLES, J. A.; MAROTI, F. A. Teletandem: crenças e respostas dos alunos. In: PINHO, S. Z.; SAGLIETTI, J. R. O. C. Núcleos de ensino da UNESP: artigos dos projetos realizados em 2006. São Paulo: Cultura Acadêmica, 2008. p.1098-1124.

XAVIER, A. C. Letramento digital e ensino. In: SANTOS, C. F.; MENDONÇA, M. (Org.). Alfabetização e letramento: conceitos e relaçóes. Belo Horizonte: Autêntica, 2007. p.133148.

Recebido em março de 2016

Aprovado em julho de 2016 